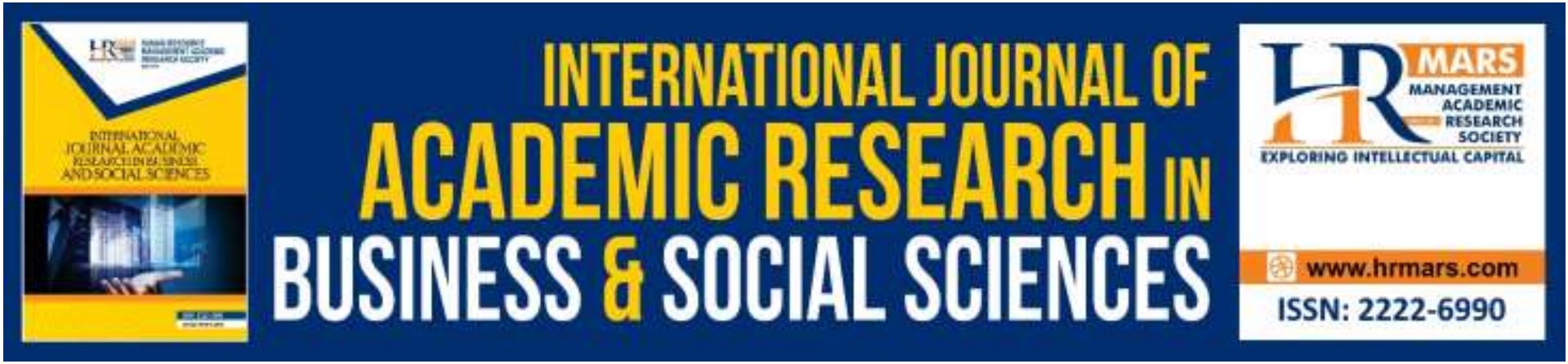

\title{
Usability Evaluation of Teacher Service Record Book System (EBRP)
}

Masitah Binti Romlee, Nor Hasbiah Ubaidullah

To Link this Article: http://dx.doi.org/10.6007/IJARBSS/v9-i9/6415

DOI: $10.6007 /$ IJARBSS/v9-i9/6415

Received: 17 July 2019, Revised: 16 August 2019, Accepted: 30 August 2019

Published Online: 21 September 2019

In-Text Citation: (Romlee \& Ubaidullah, 2019)

To Cite this Article: Romlee, M. B., \& Ubaidullah, N. H. (2019). Usability Evaluation of Teacher Service Record Book System (EBRP). International Journal of Academic Research in Business and Social Sciences, 9(9), 1214 1225.

Copyright: (C) 2019 The Author(s)

Published by Human Resource Management Academic Research Society (www.hrmars.com)

This article is published under the Creative Commons Attribution (CC BY 4.0) license. Anyone may reproduce, distribute, translate and create derivative works of this article (for both commercial and non-commercial purposes), subject to full attribution to the original publication and authors. The full terms of this license may be seen

at: http://creativecommons.org/licences/by/4.0/legalcode

Vol. 9, No. 9, 2019, Pg. 1214- 1225

http://hrmars.com/index.php/pages/detail/IJARBSS

JOURNAL HOMEPAGE

Full Terms \& Conditions of access and use can be found at http://hrmars.com/index.php/pages/detail/publication-ethics 


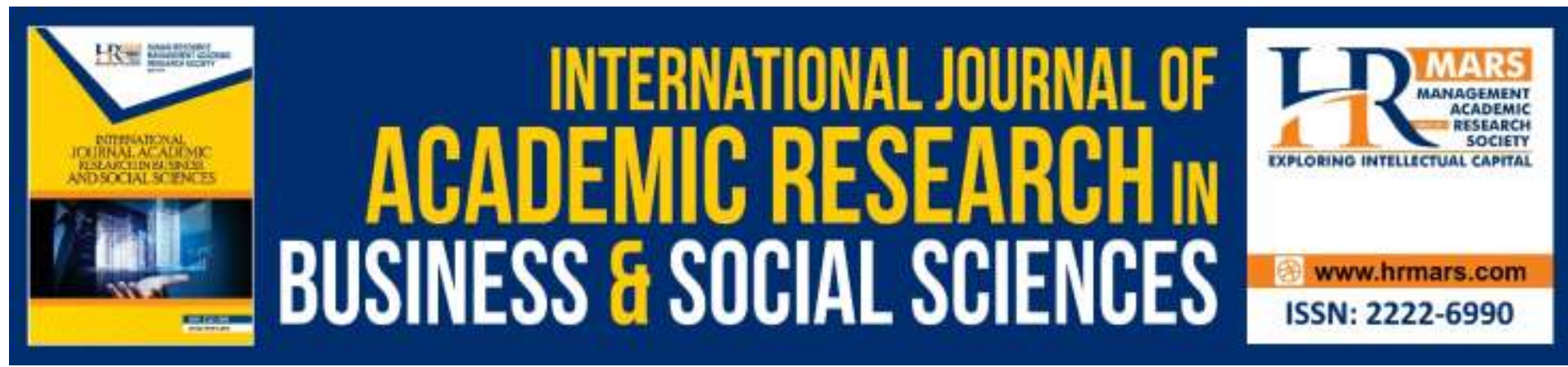

\title{
Usability Evaluation of Teacher Service Record Book System (eBRP)
}

\author{
Masitah Binti Romlee, Nor Hasbiah Ubaidullah \\ Computing Department, Faculty of Arts, Computing and Creative Industry, \\ Universiti Pendidikan Sultan Idris, 35900 Tg. Malim Perak, Malaysia
}

\begin{abstract}
Flood disaster that occurred in the Kuala Krai district has caused property damage and important data loss in government premises such as schools, rural clinics, and so on. Service record book is among the important documents that were also destroyed. This book is important because all information related to service management will be recorded in the book. A prototype of teacher service record book was built to help solve the problem of such information loss. Meanwhile, usability evaluation was conducted on the system to identify whether it meets user needs. Usability evaluation on the prototype was carried out using four attributes, namely efficiency, effectiveness, ease of learning, and security.

Keyword: Flood, Service Record Book, Usability, Usability Evaluation, Efficiency, Effectiveness, Ease of Learning, Security
\end{abstract}

\section{Introduction}

Flood disaster that happened in Kuala Krai, Kelantan in 2014 had resulted in the destruction of the data in schools. The critical data involved when the flood disaster occurred were not student data, but the teachers' data relating to Buku Rekod Perkhidmatan (eBRP). This is because the eBRP data are still kept using the method of manual storing. A prototype system was built and its usability was evaluated on the respondents involved to identify whether the prototype meets the needs of the users.

Usability can be construed as easy to use ("Usability First," 2001). Besides, it also refers to the extent to which users feel that it is easy to use in implementing a task. According to Nielsen (1993), there are two factors for evaluation of products, namely utility and usability. Usability evaluation is the method used to evaluate a product. Evaluation is carried out to identify whether the product is capable of carrying out its duties efficiently, effectively, and satisfactorily. An evaluation is done before the product is launched. This is to ensure that the issues related to a product can be identified and resolved (Gaffney, 1999). According to ("Usability Testing Basics - University of Michigan"), the main purpose of the evaluation is to understand how the product is used by the actual user and to improve products based on the results of the evaluation. 
Thus, this study is conducted to evaluate the usability of the teacher service record book system. There are four attributes of usability evaluation, namely efficiency, effectiveness, security, and ease of learning. Khalid, Pahi, \& Ahmed, 2016; Madrid, Ahmed, \& Kumar, 2019)

\section{Methodology}

Methodology is a procedure in which the researchers explain, describe, and predict the phenomena about the research undertaken (Rajasekar et al, 2013). The data collection for this study employs a qualitative approach, which is the semi-structured interview technique. Meanwhile, usability evaluation was performed based on a task analysis technique. Through this technique, the researcher is able to identify how users use the system developed.

\section{Respondents}

Four respondents, which include an officer from the District Education Office (DEO) as well as three secondary school principals in the district of Kuala Krai were involved. A purposive sampling technique was used for the selection of the four respondents. Furthermore, the three schools do not hold the Pusat Tanggungjawab (PTj) status whereby the service record book data are kept in DEO. Meanwhile, DEO was selected as respondent because the data involved are kept in DEO.

\section{Instrument}

The assessment instrument used a qualitative approach that is a semi-structured interview. Qualitative methods have various techniques in obtaining information in detail. The data collection for this study used the following instruments:

a) Developed prototype system of service record book

b) Interview checklist

In order to evaluate the aspect of usability of the developed system, the evaluation of usability attribute has been done using Web Application Usability Model From End User Perpective oleh Lew et al., (2009) with the addition of one usability attribute. Usability evaluation involves four attributes, namely efficiency, effectiveness, security, and ease of learning. Task analysis has been chosen as the method for usability evaluation because it involves interface with real users during the evaluation.

Meanwhile, the verification for question checklist was conducted by two experts with experience in the information technology industry related to software engineering and data. The experts will assess whether or not the items that will be used are appropriate by giving further comments.

In order to enhance the reliability of the study, the triangulation technique using triangulation method was used. According to Rahardjo (2010), triangulation is a method used by comparing data or information differently. The same method was applied repetitively to different respondents from three school locations as well as the District Education Office.

\section{Procedure}

The evaluation of the prototype system was conducted on four respondents, which are an officer from the Kuala Krai District Education Office and three teachers from schools in the 
district. Prior to the system evaluation, the Uniform Resource Locator (URL) for Service Record Book was given to the respondents. Respondents are able to use the prototype system beforehand and identify the function and information in the system. In order to assist the respondents, a user manual has been prepared in accordance with the respective category.

After an appointment was set, the evaluation was conducted on all four respondents. However, the researcher still explained the developed system in detail in order to ease the evaluation process. Respondents answered the questions related to usability during the interview.

\section{Findings}

Four usability attributes were evaluated, namely efficiency, effectiveness, ease of learning, and security. This evaluation is based on Web Application Usability Model From End User Perpective (Lew et al, 2009) model with the addition of an attribute value that is security.

\section{Usability Evaluation: Evaluation on Efficiency Level}

Table 1 shows the findings of the study for evaluation on the efficiency level of the eBRP prototype system and 7 evaluation aspects relating to system efficiency were assessed.

Table 1: Evaluation on the System's Efficiency Level

\begin{tabular}{|c|c|c|}
\hline Evaluation & Yes & No \\
\hline $\begin{array}{l}\text { 1. The eBRP prototype system requires a long period of } \\
\text { time to store information that is more than } 5 \text { seconds. }\end{array}$ & 0 & 4 \\
\hline $\begin{array}{l}\text { 2. The eBRP prototype system helps the primary user } \\
\text { (DEO) to access information from the secondary user } \\
\text { (teacher), tertiary user (principal), and vice versa. }\end{array}$ & 4 & 0 \\
\hline $\begin{array}{l}\text { 3. The eBRP prototype system helps users to access } \\
\text { information in a short time that is less than } 5 \text { seconds. }\end{array}$ & 4 & 0 \\
\hline $\begin{array}{l}\text { 4. There was a notification error while using the eBRP } \\
\text { prototype system. }\end{array}$ & 4 & 0 \\
\hline $\begin{array}{l}\text { 5. The eBRP prototype system helps users in the } \\
\text { management of service record book. }\end{array}$ & 4 & 0 \\
\hline $\begin{array}{l}\text { 6. The eBRP prototype system is accessible in all browsers } \\
\text { that have internet access. }\end{array}$ & 4 & 0 \\
\hline $\begin{array}{l}\text { 7. The eBRP prototype system is easily accessible at all } \\
\text { times. }\end{array}$ & 4 & 0 \\
\hline
\end{tabular}

The following findings entail the level of system efficiency in detail:

1. Long period of time to store information

For this aspect, all respondents stated otherwise because the eBRP prototype system does not require a long period of time to store information that is less than 5 seconds.

2. Helps the primary user to access information from the secondary and tertiary users All respondents agreed to this aspect because the eBRP prototype system can help the primary user (DEO) to access information from the secondary user (teacher), tertiary user 
(principal), and vice versa. This shows that the eBRP prototype system can help users to access information from the secondary and tertiary users.

3. Helps users to access information in a short time

For this aspect, all four respondents agreed that the eBRP prototype system can help users to access information in a short time that is less than 5 seconds.

4. There was an error while using the system

For the aspect of notification error, all respondents agreed that there was a notification error while using the eBRP prototype system. This notification error can help users in making a decision before an action is taken.

5. Helps users in the management of service record book

For the aspect of assisting in the management of service record book, all respondents agreed to this aspect. Through eBRP prototype system, users are able to manage service record books effectively.

6. System is accessible in internet browsers

For this aspect, all four respondents had agreed because the eBRP prototype system is accessible in all browsers that have internet access.

7. The eBRP prototype system is easily accessible at all times

For the aspect of easy access at all times, three respondents (Respondents 1, 3, and 4) agreed to the aspect while one respondent (Respondent 2 ) disagreed.

\section{Usability Evaluation: Evaluation on Effectiveness Level}

Table 2 shows the findings of the study for evaluation on the effectiveness level of the eBRP prototype system and 11 evaluation elements relating to system effectiveness were assessed. 
Table 2: Evaluation on the System's Effectiveness Level

\begin{tabular}{|c|c|c|}
\hline Evaluation & Yes & No \\
\hline 1. The eBRP prototype system is easy to use in general. & 4 & 0 \\
\hline 2. Users can easily find information via the search function. & 4 & 0 \\
\hline $\begin{array}{l}\text { 3. The eBRP prototype system facilitates the users to store } \\
\text { information. }\end{array}$ & 4 & 0 \\
\hline $\begin{array}{l}\text { 4. The eBRP prototype system facilitates the users to add } \\
\text { information. }\end{array}$ & 4 & 0 \\
\hline $\begin{array}{l}\text { 5. The eBRP prototype system facilitates the users to update } \\
\text { information. }\end{array}$ & 4 & 0 \\
\hline $\begin{array}{l}\text { 6. The eBRP prototype system facilitates the users to access } \\
\text { information. }\end{array}$ & 4 & 0 \\
\hline $\begin{array}{l}\text { 7. Users access the right information via the eBRP prototype } \\
\text { system. }\end{array}$ & 4 & 0 \\
\hline $\begin{array}{l}\text { 8. The navigation menu and sub menu help users to use the } \\
\text { system easily. }\end{array}$ & 4 & 0 \\
\hline 9. The icons used are suitable. & 4 & 0 \\
\hline 10. The interface design is appropriate and user friendly. & 4 & 0 \\
\hline $\begin{array}{l}\text { 11. The design of the interface in terms of graphic, layout } \\
\text { function, and colours are consistent. }\end{array}$ & 4 & 0 \\
\hline
\end{tabular}

The following findings entail the level of system effectiveness in detail:

1. Easy to use in general

For this aspect, the findings of the study showed that all respondents agreed that the eBRP prototype system is easy to use in general.

2. Finding the right information via the search function

For the aspect of finding the right information via the search function, all four respondents stated that information is easy to be searched via the search function in the eBRP prototype system.

3. Easy to store information

For the aspect of storing information, all four respondents stated that information can be stored easily via the eBRP prototype system.

4. Easy to add information

For the aspect of adding information, all respondents also agreed that the system enables the addition of information easily.

5. Easy to update information

For the aspect of information update, the findings of the study revealed that all respondents agreed that the eBRP prototype system facilitates user to update information.

6. Facilitates user to access information

For this aspect, all four respondents agreed that information is easy to be accessed through the use of eBRP prototype system. 
7. Users can access the right information while using the system

For this aspect, all respondents agreed that users can access the right information by using the eBRP prototype system.

8. Navigation menu and sub menu help users

For the aspect of navigation menu dan sub menu, the study revealed that the navigation menu and sub menu help users to use the system easily.

9. Icons used are suitable

For the aspect of icons, the findings of the study showed that all respondents agreed that the icons used are suitable.

10. Interface design is appropriate and user friendly

For this aspect, all respondents agreed that the design of the interface is appropriate and user friendly.

11. Interface design is consistent

For this aspect, all respondents agreed that the design of the interface in terms of graphic, layout function, and colours are consistent.

\section{Usability Evaluation: Evaluation on Ease of Learning Level}

Table 3 shows the findings of the study for evaluation on the ease of learning level of the eBRP prototype system and 10 evaluation elements relating to system's ease of learning were assessed.

Table 3: Evaluation on the System's Ease of Learning Level

\begin{tabular}{|c|c|c|}
\hline Evaluation & Yes & No \\
\hline 1. The use of the eBRP prototype system is easy to learn. & 4 & 0 \\
\hline 2. Users require special training to use the eBRP prototype system. & 2 & 2 \\
\hline $\begin{array}{l}\text { 3. The steps required in the eBRP prototype system are easy to } \\
\text { understand. }\end{array}$ & 4 & 0 \\
\hline 4. The eBRP prototype system provides help information for new users. & 4 & 0 \\
\hline $\begin{array}{l}\text { 5. Users take a long time to learn how to use the eBRP prototype } \\
\text { system. }\end{array}$ & 0 & 4 \\
\hline 6. Users require an instructor while using the eBRP prototype system. & 2 & 2 \\
\hline 7. Error messages help users while operating the system. & 4 & 0 \\
\hline 8. The use of menu helps users to access module and sub module. & 4 & 0 \\
\hline 9. The use of navigation confuses the users. & 2 & 0 \\
\hline
\end{tabular}

The following findings entail the level of system ease of learning in detail:

1. The system is easy to learn

For the aspect of ease of learning, the findings revealed that all four respondents agreed that the use of the eBRP prototype system is easy to learn.

2. Users require special training 
For the aspect of special training, two respondents seconded to the statement whereas the rest stated otherwise. Respondent 2 and Respondent 3 agreed that users require special training to use the eBRP prototype system while Respondent 1 disagreed.

3. The steps to use the system are easy to understand

For this aspect, all respondents agreed that the steps required in the eBRP prototype system are easy to understand.

4. The system provides help information

For help information, all four respondents agreed that the eBRP prototype system provides help information for new users.

5. Short time needed for users to learn the system

For the aspect of time needed to learn the system, all respondents disagreed and users need a longer time to learn how to use the eBRP prototype system.

6. Instructor is needed while using the system

For this aspect, two respondents (Respondent 2 and Respondent 3) agreed that an instructor is needed while using the system, while Respondents 1 and 4 disagreed that the eBRP prototype system requires an instructor.

7. Error messages help users

For the aspect of error messages, all respondents agreed that error messages help users while operating the system.

8. Module dan sub module can be accessed through the use of menu

For this aspect, all four respondents agreed that the use of menu helps users to access module and sub module.

9. Navigation confuses the users

For the aspect of navigation, two respondents agreed that navigation confuses the users whereas the other two stated otherwise. Respondents 2 and 4 agreed that the use of navigation confuses the users, while Respondents 1 and 3 disagreed to the statement. 


\section{Usability Evaluation: Evaluation on Security Level}

able 4 shows the findings of the study for evaluation on the security level of the eBRP prototype system and 9 evaluation elements relating to system security were assessed.

Table 4: Evaluation on the System's Security Level

\begin{tabular}{|c|c|c|}
\hline Evaluation & Yes & No \\
\hline $\begin{array}{l}\text { 1. The use of the eBRP prototype system can store information } \\
\text { securely. }\end{array}$ & 4 & 0 \\
\hline $\begin{array}{l}\text { 2. The distribution of module by user guarantees the security of } \\
\text { information in teacher service record book. }\end{array}$ & 4 & 0 \\
\hline 3. The use of FORGOT PASSWORD is effective. & 4 & 0 \\
\hline $\begin{array}{l}\text { 4. The eBRP prototype system provides restrict access function } \\
\text { based on user category. }\end{array}$ & 4 & 0 \\
\hline $\begin{array}{l}\text { 5. Users (teachers) can access information of other users while } \\
\text { operating the eBRP prototype system. }\end{array}$ & 0 & 4 \\
\hline $\begin{array}{l}\text { 6. Users (principals) can access the information of teachers from } \\
\text { other schools. }\end{array}$ & 0 & 4 \\
\hline 7. Users can update the password. & 4 & 0 \\
\hline $\begin{array}{l}\text { 8. The eBRP prototype system can be accessed by other parties } \\
\text { without permission. }\end{array}$ & 0 & 4 \\
\hline $\begin{array}{l}\text { 9. Users can access the eBRP prototype system if entering a } \\
\text { wrong user ID and password. }\end{array}$ & 0 & 4 \\
\hline
\end{tabular}

The following findings entail the level of system security in detail:

1. The system can store information securely

For the aspect of keeping information secure, all respondents agreed that the use of the eBRP prototype system can store information securely.

2. Distribution of module by user guarantees user security

For this aspect, all respondents agreed that the distribution of module by user guarantees the security of information in teacher service record book.

3. The use of 'FORGOT PASSWORD' is effective

For the aspect of user to forget password, all respondents agreed that the use of FORGOT PASSWORD is effective.

4. Restrict access function is based on user category

For this aspect, all respondents agreed that the eBRP prototype system provides restrict access function based on user category.

5. Teacher can access information of other teachers

For the aspect of teacher access, the findings of the study revealed that all respondents agreed that users (teachers) can access information of other users while operating the eBRP prototype system.

6. Principal can access the information of teachers from other schools 
For the aspect of principal access, all respondents disagreed that principal can access the information of teachers from other schools.

7. Password can be updated

For the aspect of password update, all four respondents agreed that users can update the password.

8. System is accessible without permission

For the aspect of access security, all respondents disagreed that the eBRP prototype system can be accessed by other parties without permission.

9. System is accessible if entering a wrong user ID and password

For this aspect, all four respondents disagreed that users can access the eBRP prototype system if entering a wrong user ID and password

\section{Discussion}

Usability evaluation of the system was conducted on four respondents based on the case study of this research. Prior to the assessment, the respondents were allowed to use the system beforehand. This is to ease the evaluation process so that the respondents are able to understand the system before conducting the assessment.

\section{Evaluation on the System's Efficient Level}

Based on the findings, all respondents agreed that the eBRP system is efficient. It can be seen upon the process of storing information, whereby the system does not take long to store information that is less than 5 seconds. Besides, eBRP also helps users to access necessary information in a short time. This coincides with the definition of efficient by Quesenbery: an efficient system is the system's speed level in performing duties when the user uses the system. Based on the Web Application Usability Model From End User Perpective model, efficiency is the time taken for a task to be carried out. If the duty takes a long time, it will negatively impact the efficiency of the system.

The eBRP prototype system also has an error notification where it efficiently helps users while using this system. However, access to the system should take into consideration the access to the internet. If the user is in an area that does not have an internet network, then the eBRP prototype system cannot be accessed because it is an online system.

\section{Evaluation on the System's Effectiveness Level}

Findings of the study found that the respondents agreed that eBRP is an effective system to be used. Among the factors that make eBRP an effective system is that it also has functions that help the users. Through the eBRP prototype system, users can add, update, delete, and find the information required accurately.

In addition, the use of navigation and icons also give an impact on the users in making the system effective. In fact, the design of the system is also user friendly in terms of graphics, layout functionality, and colour consistency. The constructed eBRP system is in accordance with what was stated by Lew that is an effective system is one that can perform a process 
accurately and completely while achieving aims that are specified and measured using quality troubleshooting as well as the number of mistakes made.

\section{Evaluation on the System's Ease of Learning Level}

Ease of learning refers to a system that is easy for users to learn. Findings of the study revealed that almost all respondents agreed that eBRP is a system that is easy to learn. However, there are several aspects that the respondents disagreed with. Two respondents stated that they require special training and an instructor while using the system. Further, the respondents also mentioned that the use of navigation is rather confusing.

Nevertheless, the respondents still agreed that eBRP is easy to learn. This is because eBRP provides help information for new users. Respondents also mentioned that the time needed to learn the system is not long. The constructed prototype has provided help information for users such as a user manual. In line with Nielsen's opinion, a system that is easy to learn is one by which users can easily perform the basic system developed during the first time they use it based on the discussion that is done.

\section{Evaluation on the System's Security Level}

The system security is important when developing the system. This is to enable the information to be stored securely and cannot be accessed by the liable parties. Based on the findings, all respondents agreed that eBRP is a system that is secure to be used.

In fact, the function to retrieve password is also effective. Users are also unable to access the system if entering a wrong ID and password. In addition, users also cannot access information that is not allowed because the eBRP prototype system was developed with the functions of restrict access by user category. Distribution of modules according to user guarantees the security of information of teacher service record book. In conclusion, all four respondents agreed that the eBRP prototype system is capable of storing service record information securely. This section is consistent with the purpose of information security which refers to protection against confidentiality, integrity, and access to information. The importance of security is strengthened on the basis of the opinion by Braz and Robert, that is control on the rights of access to resources and facilities information is of paramount importance with the process of validation access.

\section{Conclusion}

The service record book is an important data for each civil servant including teachers. Flood disaster that occurred had destroyed the data and caused the process of retrieving data to be difficult due to the unavailability of complete duplicate data. Through this study, the usability evaluation comprising four attributes has been evaluated on four selected respondents in Kuala Krai. The study also found that the eBRP prototype system meets the usability needs from four evaluated attributes, namely efficiency, effectiveness, security, and ease of learning. The development of the eBRP prototype system can help teachers and the District Education Office in the management of the service record book when facing flood disaster situations. 


\section{Corresponding Author}

Masitah Binti Romlee

Computing Department, Faculty of Arts, Computing and Creative Industry, Universiti Pendidikan Sultan Idris, 35900 Tg. Malim Perak, Malaysia

Email: masitahlee0692@gmail.com

\section{References}

Khalid, N., Pahi, M. H., \& Ahmed, U. (2016). Loosing your best talent: Can leadership retain employees? The dilemma of the banking sector of Hyderabad Sindh, Pakistan: A mediation investigation. International Review of Management and Marketing, 6(3), 608-616.

Madrid, D., Ahmed, U., \& Kumar, R. (2019). Examining the Impact of Classroom Environment on Entrepreneurship Education: Case of a Private University in Bahrain. Journal of Entrepreneurship Education, 22(1), 1-8.

Gaffney, G. (1999), Information \& Design, Usability Techniques series

Diamond Bullet Design, Inc. (2001). Usability first glossary. Retrieved February2, 2019, from http://www.usabilityfirst.com/glossary.

Nielsen, J. (1993). Usability engineering. New York: Academic Press, Inc.

Ahmad, A. R. (2014). Banjir 2014 Bakal Catat Sejarah Terburuk - Berita Semasa. Dicapai pada November 2, 2016, dari http://www.mstar.com.my/berita/beritasemasa/2014/12/27/sejarah-terburuk/.

Akasah, Z. A. \& Doraisamy, S. V., (2015). 2014 Malaysia Flood: Impacts \& Factors Contributing Towards the Restoration of Damages. Journal of Scientific Research and Development, Issue 2 (14) 2015, Pp. 53-59.

Rajasekar, S., Philominathanet, P. \& Chinnathambi, V. (2013). Research methodology. Physics ed-ph. 14. 1-53.

CEUR Workshop Proceedings, San Sebastian, Spain, vol. 561 (2009) ISSN 16130073, http://ceur-ws.org

Kruger, H. A. and Kearney, W. D. (2006). A Prototype for Assessing Information Security Awareness. Computers and Security, 25, 289-296

Braz, C., \& Robert, J. (2006). Security and usability: the case of the user authentication methods. 199-203. 10.1145/1132736.1132768.

Quesenbery, W. (2001) What Does Usability Mean: Looking beyond Ease of Use. Proceeding of 48th Annual Conference-Society for Technical Communication, Chicago, 13-16 May 2001.

Usability Testing Basics - University of Michigan. (n.d.). Retrieved February 12, 2019, from http://webservices.itcs.umich.edu/drupal/wwwsig/sites/webservices.itcs.umich.edu. drupal.wwwsig/files/Usability-Testing-Basics.pdf 